\title{
Preparation of Betulone Via Betulin Oxidation Over Ru Nanoparticles Deposited on Graphitic Carbon Nitride
}

\author{
N. D. Shcherban ${ }^{1,2}$ - P. Mäki-Arvela ${ }^{2}$ A. Aho ${ }^{2}$-S. A. Sergiienko ${ }^{3}$ - M. A. Skoryk ${ }^{4,5} \cdot$ E. Kolobova $^{6} \cdot$ I. L. Simakova ${ }^{7}$. \\ K. Eränen ${ }^{2} \cdot A$. Smeds $^{2} \cdot$ J. Hemming ${ }^{2} \cdot$ D. Yu. Murzin ${ }^{2}$
}

Received: 5 July 2018 / Accepted: 9 December 2018 / Published online: 17 January 2019

(c) The Author(s) 2019

\section{Abstract}

Derivatives of betulin obtained by oxidation have broad pharmacological applications, demonstrating anti-inflammatory, antioxidant, hepatoprotective, and anticancer activity. Ru supported catalysts based on graphitic carbon nitride or N-doped carbon were prepared via a mild reduction of the initial Ru precursor with hydrazine. These catalysts along with Ru supported on carbon nanofibers and a mesoporous carbon support Sibunit were studied in catalytic oxidation of betulin. Ru/carbon nitride demonstrated catalytic activity in betulin oxidation higher than Ru/N-doped carbon (conversion of betulin up to ca. 70\% and $30 \%$, respectively). Selectivity to different oxidation products was dependent on the properties of the carbon supports.

\section{Graphical Abstract}

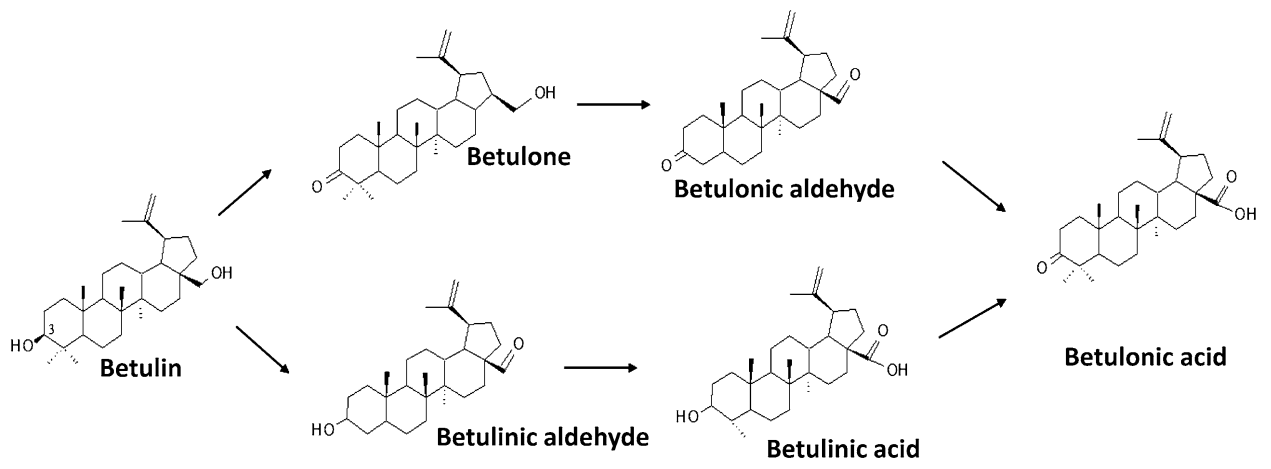

Keywords Betulin oxidation · Carbon nitride $\cdot$ Ruthenium $\cdot$ Betulone

Electronic supplementary material The online version of this article (https://doi.org/10.1007/s10562-018-02649-8) contains supplementary material, which is available to authorized users.

D. Yu. Murzin

dmurzin@abo.fi

1 L.V. Pisarzhevsky Institute of Physical Chemistry, National Academy of Sciences of Ukraine, 31 pr. Nauky, Kiev 03028, Ukraine

2 Johan Gadolin Process Chemistry Centre, Åbo Akademi University, Biskopsgatan 8, 20500 Åbo/Turku, Finland

3 National University of Science and Technology MISiS, Leninskii pr. 4, 119049 Moscow, Russia
4 NanoMedTech LLC, 68 Gorkogo str., Kiev, Ukraine

5 G.V. Kurdyumov Institute for Metal Physics, N.A.S. of Ukraine, 36 Academician Vernadskiy av., Kiev 03680, Ukraine

6 Research School of Chemistry \& Applied Biomedical Sciences, Tomsk Polytechnic University, Lenin Avenue 30, Tomsk 634050, Russia

7 Boreskov Institute of Catalysis, Lavrentieva ave. 5, Novosibirsk, Russia 


\section{Introduction}

Betulin is a natural compound from a class of lupane-type pentacyclic triterpenes possessing interesting biological properties [1-3]. Betulin derivatives obtained by oxidation (Fig. 1) have a wide spectrum of pharmacological action, which include anti-inflammatory, antioxidant, hepatoprotective, anticancer and other ones [4-10]. Lupane-type compounds have antitumor activity, among them the strongest effect is belonging to betulinic acid, which is recognized as an effective inhibitor of the growth of cancer cells [11]. Betulin, betulinic acid and betulonic acid are also interesting from the medical point of view as a basis for creation of new antiviral medicines showing inhibitory effect. Allobetulin has a moderately expressed effect on the influenza virus type B [12].

Betulonic acid is prepared via betulin oxidation in acetone with the Jones reagent [13-15]. This compound can also be obtained as a result of betulin oxidation with a pyridinedichromate complex with acetic anhydride in dimethylformamide [16] and chromium (VI) oxide in acetic acid [17].

Betulinic aldehyde is formed as a result of betulin oxidation with potassium dichromate on silica gel in dichloromethane [18]. Reaction between betulin and chlorochromate or pyridinium dichromate in dichloromethane leads to formation of betulonic aldehyde [19]. Synthesis of betulinic acid consists of reduction of betulonic acid with sodium borohydride [15] (Fig. 1). For oxidation of betulin to betulinic acid with iodine or (diacetoxyodo)benzene as oxidants, TEMPO (2,2,6,6-tetramethylpiperidine oxyl) as a catalyst was also used [20]. When $\mathrm{RuCl}_{2}\left(\mathrm{PPh}_{3}\right)_{3}$ as a homogeneous catalyst and TEMPO as a co-catalyst were also used for betulin oxidation in oxygen, the yields of betulinic aldehyde at $1 \mathrm{bar}$ and $105^{\circ} \mathrm{C}$ and $8 \mathrm{bar}$ and $100{ }^{\circ} \mathrm{C}$ were $15 \%(27 \mathrm{~h})$ and $69 \%(8 \mathrm{~h})$, respectively [21].

Use of $\mathrm{Ru} / \mathrm{C}$ as a catalyst in a mixture with the basic hydrotalcite and silicon dioxide as a dehydrating agent allowed to perform selective oxidation of betulin with synthetic air at $108{ }^{\circ} \mathrm{C}$ in toluene to betulinic aldehyde [5]. The presence of silica in the reaction mixture leads to a significant increase in the betulin conversion (41\% and $20 \%$, respectively, after $24 \mathrm{~h}$ ) with similar selectivity (67\% and $66 \%$, respectively). The use of ruthenium nanoparticles deposited on an acidic carbon support results in the formation of allobetulin as the main reaction product [5].

Another betulin derivative, betulone, is present in quite low quantities in many plants [22, 23]. Regarding its biological activity it was noted that selective oxidation of 3-hydroxyl group in the initial compound results in a significant increase in biological activity compared with betulin (regulation of melanin biosynthesis, anticancer activity etc.) $[24,25]$. Moreover, betulone can be used as the main building block for the synthesis of another valuable product allobetulone [26]. Betulone was prepared from betulin through regioselective oxidation using growing microorganism cells as catalyst [1].

Graphitic carbon nitride possessing besides interesting electronic properties also catalytic activity due to the presence of Lewis basic sites [27] seems to be a suitable support for preparation of catalysts active in betulin oxidation. The number of publications devoted to investigations of catalytic performance of $\mathrm{Ru}$ nanoparticles supported on graphitic $\mathrm{C}_{3} \mathrm{~N}_{4}$ is rather limited. For instance, $\mathrm{Ru} / \mathrm{g}$ $\mathrm{C}_{3} \mathrm{~N}_{4}$ demonstrated promising catalytic activity and a high turnover frequency number in the hydrolysis of ammonia borane which provides an eco-friendly and sustainable way to hydrogen production [28]. Deposition of $\mathrm{Pt}_{50}-\mathrm{Ru}_{50}$ alloy catalyst on nanoporous graphitic $\mathrm{C}_{3} \mathrm{~N}_{4}$ as a support allowed to increase the anodic performance in direct methanol fuel cells due to well-developed three-dimensionally interconnected porosity of the support [29].

The aim of the current study was to investigate betulin oxidation over ruthenium nanoparticles supported on graphitic carbon nitride. For comparison, nitrogen-containing carbon and several undoped carbons were also used as supports.

Fig. 1 Scheme of betulin oxidation

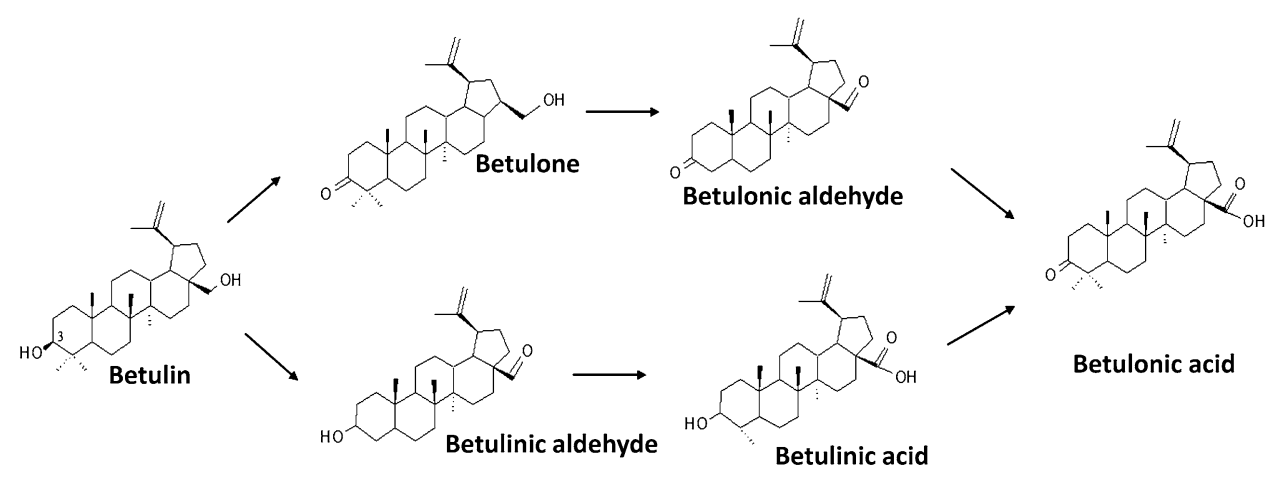




\section{Experimental}

\subsection{Sample Preparation}

Initial samples of nanostructured graphitic carbon nitride and $\mathrm{N}$-doped carbon were obtained by bulk and hard template method using melamine, as well as sucrose and melamine as precursors, respectively.

The material denoted as $\mathrm{C}_{3} \mathrm{~N}_{4}-1$ was prepared via bulk pyrolysis of melamine (Chimlaborreactiv, 99\%). For this purpose melamine was placed in the middle of the quartz tube, followed by heating in an inert atmosphere (argon) at $500{ }^{\circ} \mathrm{C}$ for $2 \mathrm{~h}$. As a result yellow carbon nitride powder was obtained. $\mathrm{C}_{3} \mathrm{~N}_{4}-2$ was synthesized using a similar technique, except that the heat treatment was carried out in air. For synthesis of $\mathrm{C}_{3} \mathrm{~N}_{4}-\mathrm{MCF}$ a weighed amount of MCF mesoporous silica was mixed with an aqueous solution containing a certain amount of melamine and hydrochloric acid (Lachema, 35\%) used for melamine binding into the salt in order to reduce its sublimation (ca. $2.356 \mathrm{~g}$ of melamine and $1.8 \mathrm{ml}$ of concentrated hydrochloric acid for $0.5 \mathrm{~g}$ of MCF). The resulting suspension was stirred on a magnetic stirrer at a room temperature for $3 \mathrm{~h}$ and dried at $40{ }^{\circ} \mathrm{C}$ for $12 \mathrm{~h}$. The obtained composite was then subjected to heat treatment in argon at $600{ }^{\circ} \mathrm{C}$ for $2 \mathrm{~h}$. For a more complete filling of the hard template pores with the substance after pyrolysis a second impregnation step of the composite with melamine was performed using the same procedure. The silica component was removed by treatment of the obtained composites with 15\% HF (Merck, $40 \%$ ) solution for $12 \mathrm{~h}$. Carbon nitride was filtered and washed to a neutral $\mathrm{pH}$ value, and then dried at $100^{\circ} \mathrm{C}$. For synthesis of $\mathrm{N}$-doped carbon (C_M sample) the product of bulk carbonization of sucrose at $900{ }^{\circ} \mathrm{C}$ for $2.5 \mathrm{~h}$ was used as the initial material. For doping of the carbon structure with nitrogen $3 \mathrm{~g}$ of the obtained carbon was treated with ethanol solution of melamine ( $2 \mathrm{~g}$ of melamine in $10 \mathrm{~mL}$ of ethanol) and stirred at a room temperature for $5 \mathrm{~h}$. The obtained suspension was boiled in order to evaporate alcohol and then the mixture was dried at $120^{\circ} \mathrm{C}$. The impregnated carbon was heated in argon atmosphere up to $950{ }^{\circ} \mathrm{C}$ (heating rate $10{ }^{\circ} \mathrm{C} / \mathrm{min}$ ) and kept at this temperature for $0.5 \mathrm{~h}$. Then the sample was washed with hot distilled water to neutral $\mathrm{pH}$ of wash water in order to remove any excess of melamine decomposition products.

In order to avoid significant changes in the chemical nature of the support surface, ruthenium nanoparticles were deposited using a mild reduction of the initial Ru precursor with a chemical reducing agent (hydrazine) similar to an approach described in [30]. A weighted amount of ruthenium trichloride $(0.0409 \mathrm{~g})$ (Merck, $99.98 \%)$, based on the content in the composite of $5 \mathrm{wt} \%$, was dissolved in $250 \mathrm{ml}$ of deionized water. The support sample $(0.3 \mathrm{~g})$ was added to the resulting solution and stirred at a room temperature for ca. $16 \mathrm{~h}$. After water evaporation the residue was dried at $120^{\circ} \mathrm{C}$ for $3 \mathrm{~h}$. The resulting sample was stirred in $100 \mathrm{ml}$ of $0.1 \mathrm{M} \mathrm{KOH}$ (Merck, 85\%) solution at a room temperature for $10 \mathrm{~min}$, thereafter hydrazine (Merck, $80 \%$ ) was added (molar ratio of hydrazine:ruthenium was 2), slowly heated up to $80^{\circ} \mathrm{C}$, and maintained at this temperature for $1 \mathrm{~h}$. The sample was filtered, washed with distilled water to a neutral $\mathrm{pH}$ of wash water and dried at $100^{\circ} \mathrm{C}$.

Two Ru catalysts were synthesized using different undoped carbons: carbon nanofibers of the platelet structure (CNF-Pl) (fraction 50-120m, FutureCarbon GmbH, R141402333-01) and a mesoporous carbon material Sibunit (fraction $50-120 \mathrm{~m}$ ). The catalyst denoted as Ru-CNF (2 wt \% $\mathrm{Ru}$ ) was prepared by immobilization on CNF-Pl colloidal Ru nanoparticles $(0.1 \mathrm{M})$ synthesized by the polyol method using $\mathrm{RuCl}_{3} \cdot \mathrm{nH}_{2} \mathrm{O}$ and ethylene glycol (EG) as a metal precursor and a reducing agent, respectively, and polyvinylpyrrolidone (PVP) as a stabilizing agent. As a general procedure, $\mathrm{RuCl}_{3} \cdot \mathrm{nH}_{2} \mathrm{O}$ and $\mathrm{PVP}(\mathrm{mol} \mathrm{Ru} / \mathrm{mol}$ monomers $\mathrm{PVP}=1 / 5$ ) were dissolved in EG under stirring followed by heating up to $198^{\circ} \mathrm{C}$ for $1 \mathrm{~h}$. Ru nanoparticles supported on CNF-Pl were subjected to thermal treatment in air at $180{ }^{\circ} \mathrm{C}$ with a temperature ramp $10 \mathrm{~K} / \mathrm{min}$ during $0.5 \mathrm{~h}$ followed by reduction in hydrogen at $250{ }^{\circ} \mathrm{C}$ with temperature ramp $1.5 \mathrm{~K} / \mathrm{min}$ during $1 \mathrm{~h}$ to remove excess of PVP [31]. The catalyst denoted as Ru-Sib-Imp (3 wt\%) was prepared by impregnation of Sibunit with $\mathrm{RuCl}_{3} \times \mathrm{nH}_{2} \mathrm{O}$ aqueous solution $(0.1 \mathrm{M})$ [32] followed by oxidation in air at $150^{\circ} \mathrm{C}$ during $1.5 \mathrm{~h}$ and reduction in hydrogen until $440{ }^{\circ} \mathrm{C}$ during $6 \mathrm{~h}$ with temperature ramp $10 \mathrm{~K} / \mathrm{min}$. The metal loading in those catalysts was measured by XRF.

\subsection{Characterization}

Phase composition of the samples was analyzed using Bruker D8 Advance diffractometer equipped with $\mathrm{Cu} \mathrm{K}_{\alpha}$ $(\lambda=0.15406 \mathrm{~nm}) \mathrm{X}$-ray source, in the range of $2 \theta=3^{\circ}-60^{\circ}$ at a scan rate of $1 \mathrm{deg} / \mathrm{min}$.

Morphology of the samples was investigated using scanning electron microscopy (SEM) with MIRA3 TESCAN microscope at accelerating voltage of $5-20 \mathrm{kV}$.

TEM images were obtained using the field emission TEM JEM-2100 (JEOL) with an accelerating voltage of $100 \mathrm{kV}$. The samples for TEM were ground in agate mortar with ethanol, and then the suspension was deposited on a copper grid coated with a carbon film.

Porous texture characterization of the carbon nitride and carbon samples was carried out by nitrogen physisorption at $-196{ }^{\circ} \mathrm{C}$ using Sorptomatic 1990 after outgassing the samples at $200^{\circ} \mathrm{C}$ under vacuum for $4 \mathrm{~h}$. The total surface area, 
$\mathrm{S}_{\mathrm{BET}}$, was calculated using the BET equation [33]. Mesopore size was determined using the Barrett-Joyner-Halenda method from the desorption branch of the isotherm [34]. The micropore size was calculated according to the Horvath-Kawazoe equation [35].

XPS-analysis of the samples was made using PerkinElmer PHI 5400 spectrometer with a $\mathrm{Mg} \mathrm{K}_{\alpha} \mathrm{X}$-ray source operated at $14 \mathrm{kV}$ and $200 \mathrm{~W}$. The samples were kept in the preparation chamber of the XPS equipment overnight before analysis. The pass energy of the analyzer was $17.9 \mathrm{eV}$ and the energy step $0.1 \mathrm{eV}$. The charging was adjusted according to the $\mathrm{C}-\mathrm{C}$ bond at $284.5 \mathrm{eV}$. Peak fitting was performed with the program XPS Peak 4.1. The background was corrected with the Shirley function.

Semi-quantitative analysis of metal concentrations was performed using wavelength dispersive X-ray fluorescence (WDXRF) spectrometry with the powder pellet method. Undiluted samples $(0.5 \mathrm{~g})$ were milled and put in the $29 \mathrm{~mm}$ diameter die. The intensities of the metal lines in the samples were measured in vacuum conditions on an ARL Advant'X spectrometer equipped with a rhodium anode X-Ray tube. Excitation conditions were as follows: tube voltage of $50 \mathrm{kV}$; current of $40 \mathrm{~mA}$; collimator with a divergence of $0.25^{\circ}$; LiF200 crystal was used as a monochromator; scintillation counter was used as a detector; counting time was $12 \mathrm{~s}$. The content of elements in the sample was estimated using a semi-quantitative method by means of a QuantAS program for standard-less analysis.

The basicity of the tested materials was determined by temperature programmed desorption of $\mathrm{CO}_{2}$ using a Micromeritics Autochem 2910 equipment. Prior to adsorption of $\mathrm{CO}_{2}$ a sample was heated to $400{ }^{\circ} \mathrm{C}\left(10{ }^{\circ} \mathrm{C} / \mathrm{min}\right)$ in a $10 \mathrm{ml} / \mathrm{min}$ flow of helium and kept at this temperature for $60 \mathrm{~min}$. Thereafter, the sample was cooled to ambient temperature and $\mathrm{CO}_{2}$ was adsorbed to the catalyst for $30 \mathrm{~min}$ with a $50 \mathrm{ml} / \mathrm{min}$ flow. After $\mathrm{CO}_{2}$ adsorption the sample was flushed with helium $(20 \mathrm{ml} / \mathrm{min})$ for $30 \mathrm{~min}$ to remove physisorbed $\mathrm{CO}_{2}$. The temperature programmed desorption was carried out with a $10{ }^{\circ} \mathrm{C} / \mathrm{min}$ heating rate until $600{ }^{\circ} \mathrm{C}$, the TCD signal was recorded every second.

\subsection{Catalytic Tests}

Betulin (90-94\% purity) was extracted from birch with a nonpolar solvent and recrystallised from 2-propanol following the literature procedure [36]. Betulin oxidation was performed over synthesized Ru catalysts at a temperature of $140{ }^{\circ} \mathrm{C}$ and atmospheric pressure using a batch-mode operated glass reactor. Synthetic air (AGA, 20\% oxygen, $80 \%$ nitrogen) was used as an oxidant, mesitylene-as a solvent. In a typical catalytic experiment, betulin oxidation was carried out using $200 \mathrm{mg}$ of reagent in $100 \mathrm{ml}$ of solvent, as well as $200 \mathrm{mg}$ of catalyst. Before the reaction, the catalyst was heated to $200{ }^{\circ} \mathrm{C}$ in an argon atmosphere for $60 \mathrm{~min}$.

The samples were taken at different time intervals. Before analysis of the samples by gas chromatography (GC), a sample of $0.5 \mathrm{ml}$ was silylated using $N, O$-Bis(trimethylsilyl) trifluoroacetamide, BSTFA (Acros, $>98 \%$ ), $100 \mu \mathrm{l}$, and trimethylchlorosilane, TMCS (Fluka, $>99 \%$ ), $25 \mu \mathrm{l}$, and pyridine (VWR Chemicals, >99\%) $25 \mu$ l, respectively, at $70{ }^{\circ} \mathrm{C}$ for $1 \mathrm{~h}$. The silylated reaction mixtures were analyzed with a gas chromatograph using HP-1 column ( $25 \mathrm{~m}$, $200 \mu \mathrm{m}, 0.11 \mu \mathrm{m})$ applying the following temperature program: $120{ }^{\circ} \mathrm{C}(1 \mathrm{~min})-6{ }^{\circ} \mathrm{C} / \mathrm{min}-320^{\circ} \mathrm{C}(15 \mathrm{~min})$ and a split ratio of $25: 1$. The injector temperature was $260^{\circ} \mathrm{C}$ and the detector temperature was $320^{\circ} \mathrm{C}$. The products were confirmed by GC-MS using HP-5 column.

\section{Results and Discussion}

Pyrolysis of melamine leads to the formation of structures with high-angle peaks $\left(2 \theta \sim 27.3-27.7^{\circ}\right)$ on the X-ray diffraction patterns (Fig. 2) corresponding to the average interlayer distance of $d=0.327-0.322 \mathrm{~nm}$ similar to the (002) plane of graphitic carbon nitride. The average crystallite sizes calculated according to the broadening of (002) peak by the Scherrer's formula [37] are ca. 6-7 nm. Synthesized carbon, doped with nitrogen (C_M), is an amorphous material because the corresponding $\mathrm{X}$-ray diffraction pattern does not contain any reflexes, including those ones characteristic for the graphite structure.

According to SEM-images (Fig. 3a) carbon nitride obtained by bulk pyrolysis consists of relatively large monolithic particles (from $200 \mathrm{~nm}$ to a few microns). Carbon nitride prepared using silica template $\left(\mathrm{C}_{3} \mathrm{~N}_{4}-\mathrm{MCF}\right)$ is

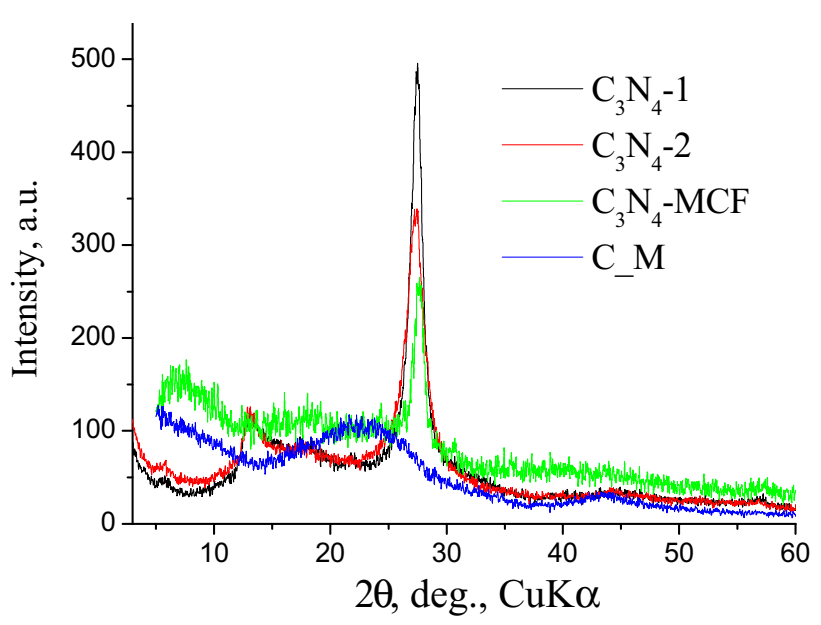

Fig. 2 X-ray diffraction patterns of the obtained carbon nitride and nitrogen-doped carbon samples 

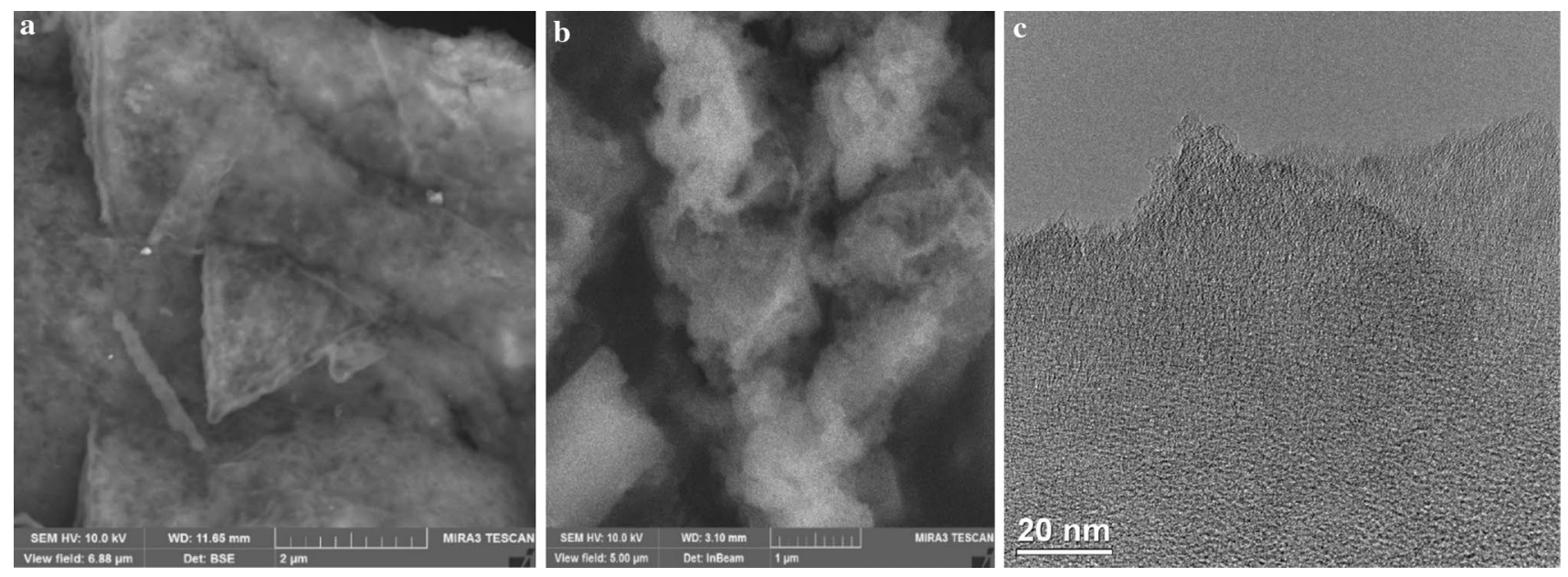

Fig. 3 SEM- and TEM-images of the obtained samples: SEM: $\mathbf{a ~ C}_{3} \mathrm{~N}_{4}-1, \mathbf{b} \mathrm{C}_{3} \mathrm{~N}_{4}-\mathrm{MCF}$; TEM: $\mathbf{c}$ C_M

characterized by a more friable structure (Fig. 3b). Such slightly more developed structure apparently can be due to the presence of silica acting as a template during the thermal treatment. $\mathrm{N}$-doped carbon $\left(\mathrm{C}_{-} \mathrm{M}\right)$ is characterized by a well-developed structure possessing slit-like micropores with a size of ca. $0.5 \mathrm{~nm}$ (Fig. 3c).

The textural characteristics of the prepared carbon nitride and $\mathrm{N}$-doped carbon calculated from nitrogen adsorption-desorption isotherms are presented in Table 1. $\mathrm{C}_{3} \mathrm{~N}_{4}-1$ and $\mathrm{C}_{3} \mathrm{~N}_{4}-2$ contain large mesopores ( $\mathrm{D}_{\text {meso }}$ $40-50 \mathrm{~nm}) . \mathrm{C}_{3} \mathrm{~N}_{4}-\mathrm{MCF}$ possesses smaller mesopores $\left(\mathrm{D}_{\text {meso }}\right.$ ca. $\left.30 \mathrm{~nm}\right)$ which can be associated with the presence of the template in comparison with carbon nitride prepared via traditional melamine bulk pyrolysis.

Application of silica template (mesoporous cellular foam $\mathrm{MCF}$ ) results in some increase of carbon nitride porosity, in particular BET specific surface area $\left(22 \mathrm{~m}^{2} / \mathrm{g}\right)$ and pore volume $\left(0.16 \mathrm{~cm}^{3} / \mathrm{g}\right)$ compared to typical $\mathrm{C}_{3} \mathrm{~N}_{4}$ $\left(10 \mathrm{~m}^{2} / \mathrm{g}\right.$ and $0.04 \mathrm{~cm}^{3} / \mathrm{g}$, respectively, Table 1$)$. Completely mesoporous structures (without micropores) of the prepared carbon nitride samples should be noted.

$\mathrm{N}$-doped carbon (C_M) is a homogeneously microporous material with the micropore volume of $0.17 \mathrm{~cm}^{3} / \mathrm{g}$. Micropores $\left(D_{\text {micro }} \leq 1 \mathrm{~nm}\right)$ constitute $85 \%$ of the total pore volume testifying a high uniformity of microporous structure in the obtained sample (Table 1).

Temperature-programmed desorption curves of carbon dioxide (TPD $\mathrm{CO}_{2}$ ) from synthesized $\mathrm{g}-\mathrm{C}_{3} \mathrm{~N}_{4}$ and nitrogendoped carbon samples contain one main maximum of carbon dioxide desorption at ca. $130-160{ }^{\circ} \mathrm{C}$ (Fig. 4a). Deconvolution of the indicated curves (Fig. 7 b) using the Gaussian distribution function gives two main peaks with the temperature maxima of carbon dioxide desorption at ca. $90-100{ }^{\circ} \mathrm{C}$ and $130-160{ }^{\circ} \mathrm{C}$, which can be attributed to physisorption and adsorption of $\mathrm{CO}_{2}$ on weak basic sites, respectively. The corresponding concentrations of the basic sites without taking into account the physically adsorbed carbon dioxide are ca. 40-80 $\mu \mathrm{mol} / \mathrm{g}$ (shoulder with the $\mathrm{CO}_{2}$ desorption maximum at $130-160^{\circ} \mathrm{C}$ ).

Deposition of ruthenium trichloride followed by reduction leads to formation of ruthenium nanoparticles with a diameter ranging from 1 to $5 \mathrm{~nm}$ (Fig. 5) which is close to the particle sizes obtained in [32]. It should be noted that carbon nitride contributes to the formation of relatively homogeneous nanoparticles (maxima of particle size distribution are 1.7, 1.3, 4.0 and $1.6 \mathrm{~nm}$ for $\mathrm{Ru}-\mathrm{C}_{3} \mathrm{~N}_{4}-1$, $\mathrm{Ru}-\mathrm{C}_{3} \mathrm{~N}_{4}-2, \mathrm{Ru}-\mathrm{C}_{3} \mathrm{~N}_{4}-\mathrm{MCF}$ and $\mathrm{Ru}-\mathrm{C}_{-} \mathrm{M}$, respectively, Fig. 5), which can be connected with stabilizing effect of the carbon nitride surface [38]. The average particle sizes
Table 1 Structural-sorption characteristics of supports $\left(\mathrm{N}_{2}\right.$, 77 K)

\begin{tabular}{lllllll}
\hline Sample & $V_{\text {micro }}, \mathrm{cm}^{3} / \mathrm{g}$ & $V_{\text {meso }}, \mathrm{cm}^{3} / \mathrm{g}$ & $D_{\text {meso }}, \mathrm{nm}$ & $\mathrm{S}_{\text {meso }}, \mathrm{m}^{2} / \mathrm{g}$ & $S_{\text {BET }}, \mathrm{m}^{2} / \mathrm{g}$ & $\mathrm{V}_{\text {ads }}, \mathrm{cm}^{3} / \mathrm{g}$ \\
\hline $\mathrm{C}_{3} \mathrm{~N}_{4}-1$ & 0.003 & 0.04 & 38 & 10 & 10 & 0.04 \\
$\mathrm{C}_{3} \mathrm{~N}_{4}-2$ & - & 0.06 & $\sim 50$ & 10 & 10 & 0.06 \\
$\mathrm{C}_{3} \mathrm{~N}_{4}-\mathrm{MCF}$ & - & 0.16 & 33 & 19 & 22 & 0.16 \\
$\mathrm{C}_{-} \mathrm{M}$ & 0.17 & - & - & - & 630 & 0.20 \\
Sibunit & & & & & 350 & 0.56 \\
CNF-PI & & & & & 123 & 0.29 \\
\hline
\end{tabular}



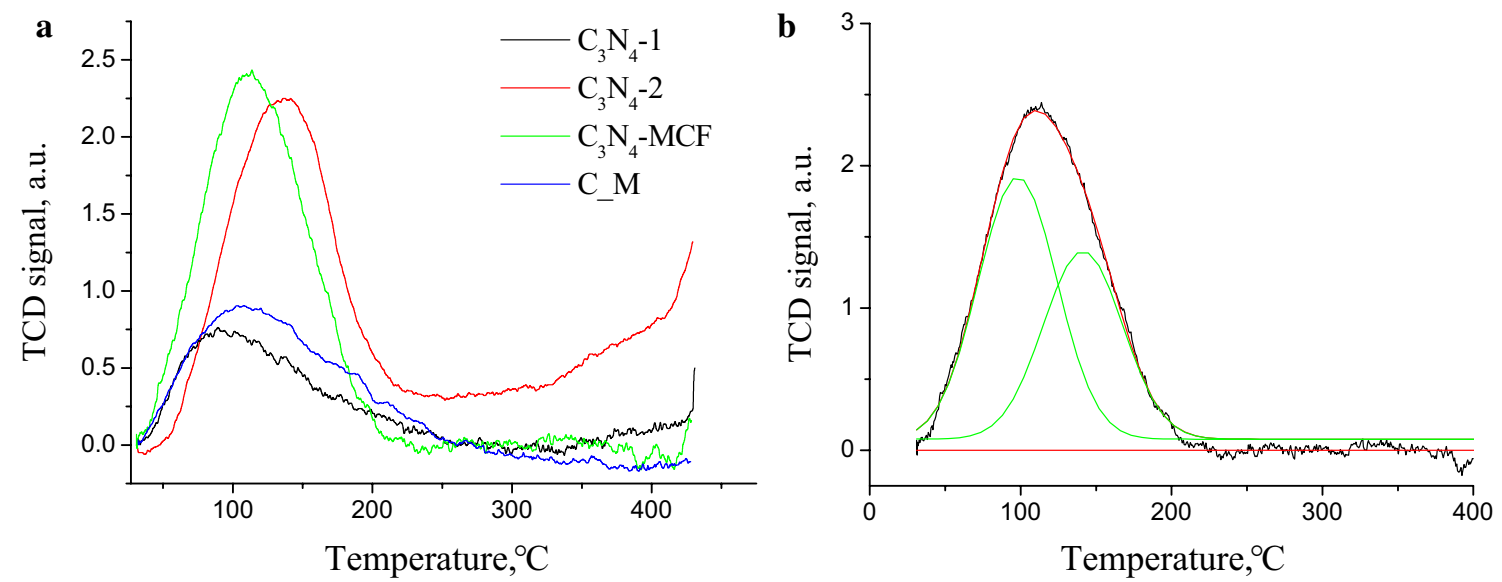

Fig. $4 \mathrm{CO}_{2}$-TPD profiles for the prepared carbon nitride and carbon samples (a) and deconvolution for $\mathrm{C}_{3} \mathrm{~N}_{4}-\mathrm{MCF}(\mathbf{b})$

for Ru-CNF and Ru-Sib-Imp catalysts were 2.5 and $1.3 \mathrm{~nm}$ respectively.

The chemical state of Ru in the obtained composites was characterized by XPS (Fig. 6). Ru 3d XPS spectra (Fig. 6 a, b) consist of two main peaks at binding energies 280.7 and $280.2 \mathrm{eV}$ assigned to $\mathrm{Ru}(4+)$ of the ruthenium oxide $\left(\mathrm{RuO}_{2}\right)$ and the $\mathrm{Ru}(0)$ metal peak, respectively [39, 40]. Formed Ru particles being quite small (mainly $2-4 \mathrm{~nm}$ ) are exposed to surface oxidation, therefore resulting in the formation of a core-shell structures [39]. In fact a high content of $\mathrm{Ru}$ in a high oxidation state is observed even in classical $\mathrm{Ru} / \mathrm{C}$ catalysts and $\mathrm{Ru} / \mathrm{CNT}$ after hydrogenation of sugars [41, 42]. Other peaks belong to $\mathrm{C} 1 \mathrm{~s}$ region of the support. In particular, two main peaks at 284.5 and $287.9 \mathrm{eV}$ (Fig. 6a, b) correspond to $\mathrm{sp}^{2} \mathrm{C}-\mathrm{C}$ bonds and $\mathrm{sp}^{2}$-bonded carbon in $\mathrm{N}$-containing aromatic rings $(\mathrm{N}-\mathrm{C}=\mathrm{N})$ [43]. $\mathrm{Ru}$ 3p XPS spectra, compared to Ru 3d spectra, do not overlap with other signals allowing monitoring the oxidation state (Fig. 6c, d). These spectra can be deconvoluted into three peaks. The peak at a binding energy of $461.2 \mathrm{eV}$ can be attributed to $\mathrm{Ru}(0)$ from metal atoms, at $463.0-463.5 \mathrm{eV}$ to $\mathrm{RuO}_{2}$ and at $465.8-466.3 \mathrm{eV}$ to $\mathrm{RuO}_{\mathrm{x}}[39,40]$.

Catalytic activity of Ru supported catalysts based on the graphitic carbon nitride and $\mathrm{N}$-doped carbon was tested in the betulin oxidation with synthetic air. In order to compare the influence of the support nature and porosity, Ru catalysts supported on different undoped carbons (mesoporous Sibunit and carbon nanofibers) were also investigated.

$\mathrm{Ru} /$ carbon nitride possesses catalytic activity in betulin oxidation higher than Ru/N-doped carbon (ca. 70\% and 30\% conversion of betulin, respectively, Table 2). Probably, it can be due to several reasons: (1) a significant fraction of defects serving as active sites as well as presence of weak Lewis basic sites on the surface of carbon nitride, (2) better dispersion of the Ru nanoparticles and (3) more effective mass transfer compared to only microporous $\mathrm{Ru} / \mathrm{N}$-doped carbon. Betulone was the main desired product over the studied catalysts (selectivity up to $27 \%$ ). The mass spectrum of betulone is presented in SI. The peaks of by-products in GC-MS are very small and therefore their identification is very challenging. In general, by-products were represented by several esters/ethers. Utilization of Ru-CNF prepared by the colloidal method resulted in a much less active catalyst forming mainly betulone (33\% selectivity) while Ru-SibImp afforded higher conversion that Ru-CNF not, however, comparable with $\mathrm{Ru} /$ carbon nitride catalysts. Selectivity to betulinic aldehyde was at the same time the highest (ca. $15 \%$ ) especially considering that conversion was lower for $\mathrm{Ru}$-Sib-Imp than in the case of $\mathrm{Ru}-\mathrm{C}_{3} \mathrm{~N}_{4}$ (Table 2).

Typical kinetic plots showing the main identified components in the reaction mixture are presented in Fig. 7. As can be seen from the kinetic curves $\mathrm{Ru}-\mathrm{C}_{3} \mathrm{~N}_{4}-\mathrm{MCF}$ allows achieving a more rapid betulin transformation and formation of the reaction products (betulone, betulonic aldehyde, betulonic acid, betulinic aldehyde, betulinic acid, lupeol) in higher concentrations than Ru deposited on N-doped carbon and undoped carbons. However faster formation of other (unidentified) products should be noted which can be due to an overall higher catalytic activity of $\mathrm{Ru}-\mathrm{C}_{3} \mathrm{~N}_{4}-\mathrm{MCF}$ resulting in generation of side products together with the desired ones. Application of Ru nanoparticles supported on a conventional carbon support $(\mathrm{Ru} / \mathrm{C}$, Degussa) as a catalyst results in a predominant formation of allobetulin (selectivity $72 \%$, conversion $54 \%$ ) which was assigned to acidic sites inherent to the support [5]. Use of basic supports (i.e. carbon nitride and $\mathrm{N}$-doped carbon) allows avoiding allobetulin generation and it can be possibly responsible for higher oxidation activity involving basic sites. Better catalytic performance of $\mathrm{Ru}-\mathrm{C}_{3} \mathrm{~N}_{4}-\mathrm{MCF}$ in comparison with $\mathrm{Ru}-\mathrm{C}_{3} \mathrm{~N}_{4}-1$ and $\mathrm{Ru}-\mathrm{C}_{3} \mathrm{~N}_{4}-2$ manifested in increased selectivity toward the desired products (Table 2) can be associated with a better developed porosity (Table 1) and reticulated structure 

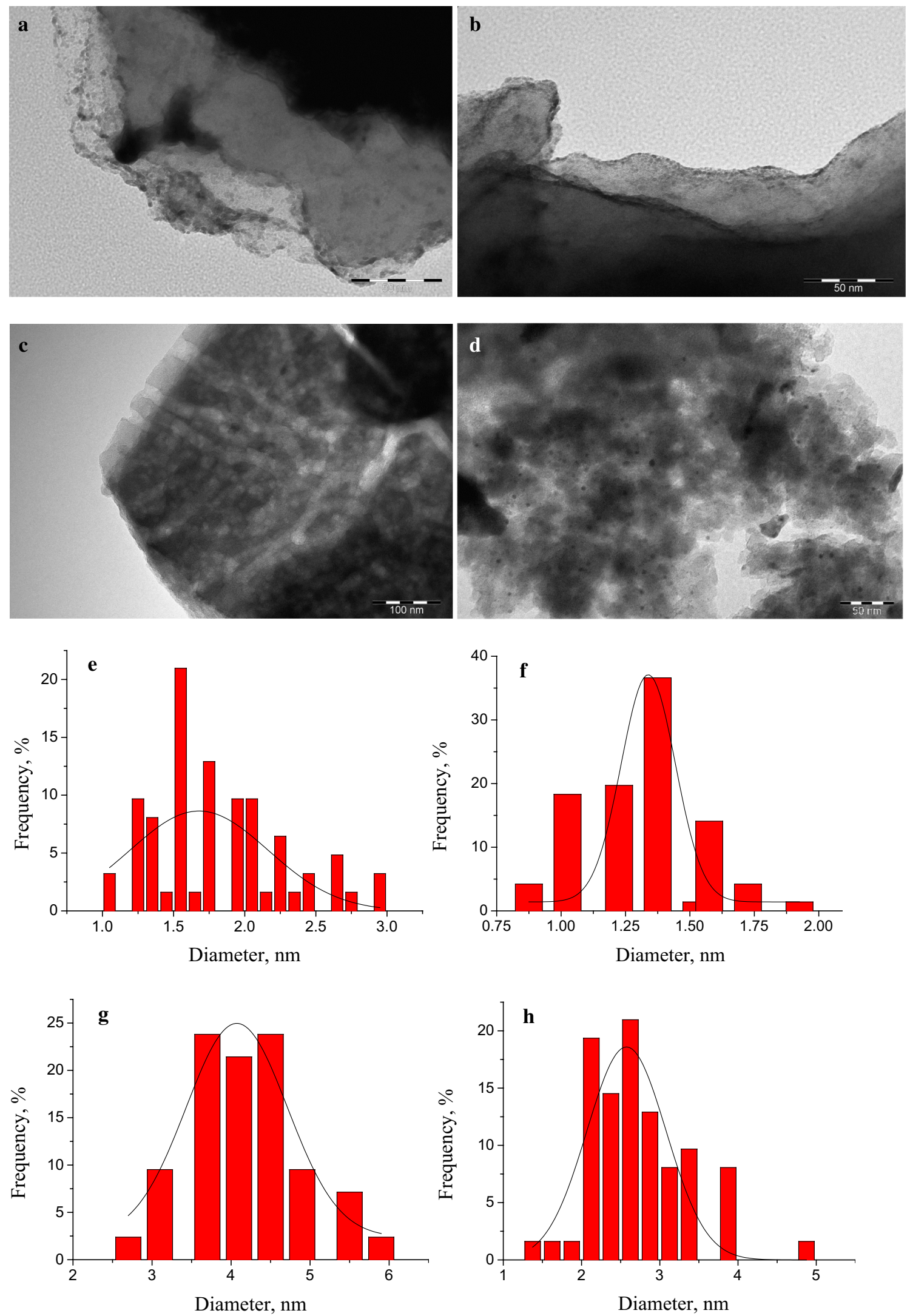

Fig. 5 TEM-images and particle size distributions for the composites based on graphitic carbon nitride or nitrogen-doped carbon with ruthenium nanoparticles: a, e Ru-C $\mathrm{C}_{3} \mathrm{~N}_{4}-1$, b, f Ru- $\mathrm{C}_{3} \mathrm{~N}_{4}-2$, c, g Ru-C $\mathrm{C}_{3} \mathrm{~N}_{4}-\mathrm{MCF}, \mathbf{d}, \mathbf{h} \mathrm{Ru}-\mathrm{C} \_\mathrm{M}$ 

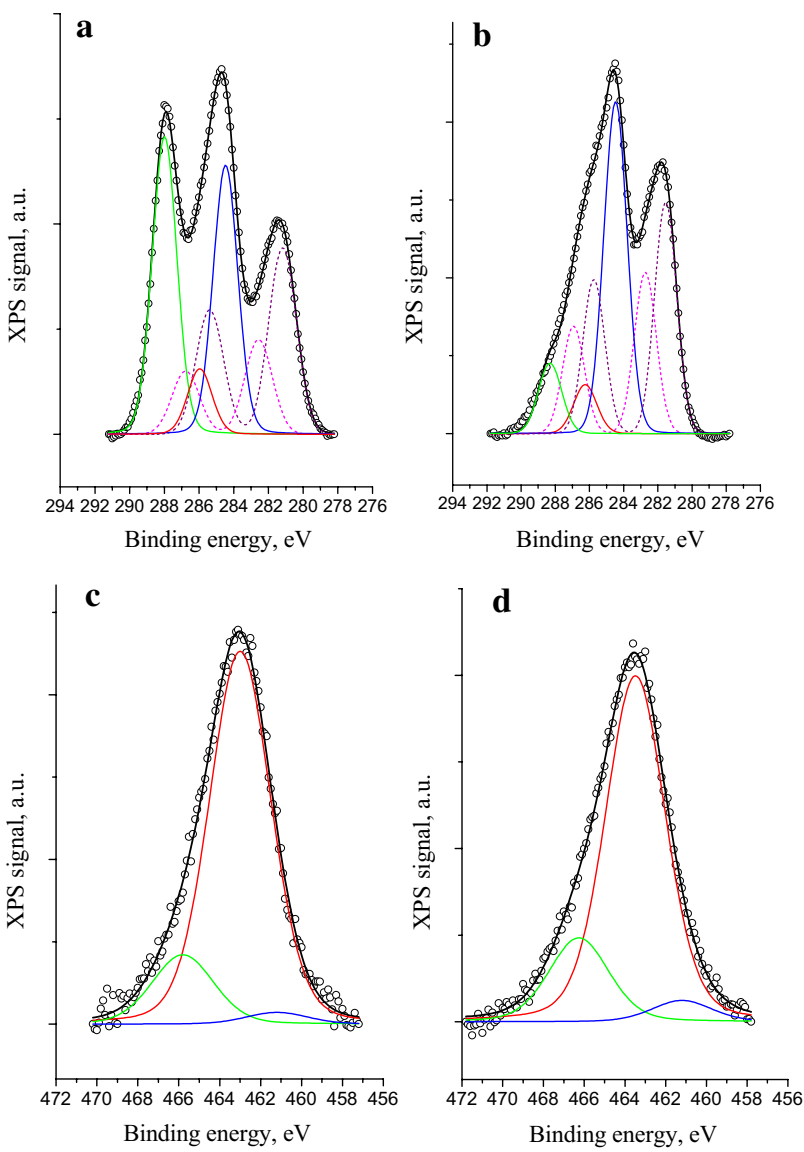

Fig. 6 XPS spectra of Ru 3d (a, b) and Ru 3p (c, d) regions for $\mathrm{Ru}-$ $\mathrm{C}_{3} \mathrm{~N}_{4}-2(\mathbf{a}, \mathbf{c})$ and $\mathrm{Ru}-\mathrm{C} \_\mathrm{M}(\mathbf{b}, \mathbf{d})$

(Fig. 4c) of $\mathrm{Ru}-\mathrm{C}_{3} \mathrm{~N}_{4}-\mathrm{MCF}$ obtained via the hard-templating method.

Selectivity towards betulone as a function of betulin conversion presented in Fig. 8, contains maxima, testifying probably intensification of the side products formation.

Comparing the catalytic results it can be suggested that the presence of weak basic sites in the structure of the support (carbon nitride and $\mathrm{N}$-doped carbon) increases the betulin conversion, while application of the carbon supports with a developed porosity (Ru-Sib-Imp) leads to an increase of selectivity not only towards betulone, but also towards another important product—betulinic aldehyde (Table 2).

There are available data in the literature on the preparation of betulone from betulin using microorganisms. For example, the yield of betulone was up to $25 \%$ at $33{ }^{\circ} \mathrm{C}$ after 6 days [1]. Data on the preparation of betulone from betulin using heterogeneous catalysts according to our knowledge are absent. The maximal yield of betulone achieved in the current study is ca. $14 \%$ after $3 \mathrm{~h}$ using $\mathrm{Ru}-\mathrm{C}_{3} \mathrm{~N}_{4}-\mathrm{MCF}$ as the catalyst. The obtained data can be used for further investigation and improvement of the catalytic performance of $\mathrm{Ru}$ supported heterogeneous catalysts in betulin oxidation to useful pharmaceutical products including betulone.

It should be noted that, as a result of catalytic experiments, the reaction mixture became yellow, which according to GC-MS data was due to partial oxidation of the solvent (mesitylene) to 3,5-dimethylbenzoic acid.

High oxidative activity of the prepared materials and formation of betulone can be associated with the presence of $\mathrm{RuO}_{2}$ in the nanoparticles, which in accordance with [39] is extremely active for CO oxidation. The size effect of catalytic activity for Ru nanoparticles within the 2-7 nm size range was correlated with the stability of the core-shell structure [44].

\section{Conclusions}

Ru nanoparticles were deposited on graphitic carbon nitride, $\mathrm{N}$-doped carbon and mesoporous carbons. It has been shown that Ru supported on a hard-templated carbon nitride exhibited higher catalytic activity in the betulin oxidation than $\mathrm{Ru} / \mathrm{N}$-carbon composites, which can be probably attributed to a significant fraction of weak basic sites required for oxidation. Formation of betulone as the main desired reaction product (selectivity up to $27 \%$ with the yield reaching ca. $14 \%$ after $3 \mathrm{~h}$ ) over heterogeneous Ru supported catalysts was demonstrated.
Table 2 Catalytic behaviour of $\mathrm{Ru}$ containing catalysts in betulin oxidation

\begin{tabular}{lccllllr}
\hline Catalyst & $\mathrm{X}(\%)$ & $\mathrm{S}_{1}(\%)$ & $\mathrm{S}_{2}(\%)$ & $\mathrm{S}_{3}(\%)$ & $\mathrm{S}_{4}(\%)$ & $\mathrm{S}_{5}(\%)$ & $\mathrm{Y}_{1}(\%)$ \\
\hline $\mathrm{Ru}-\mathrm{C}_{3} \mathrm{~N}_{4}-1$ & 82.6 & 9.8 & 1.2 & 2.8 & 1.3 & 4.0 & 8.1 \\
$\mathrm{Ru}-\mathrm{C}_{3} \mathrm{~N}_{4}-2$ & 72.9 & 7.2 & 0 & 2.7 & 3.6 & 8.9 & 5.3 \\
$\mathrm{Ru}-\mathrm{C}_{3} \mathrm{~N}_{4}-\mathrm{MCF}$ & 67.3 & 23.4 & 8.5 & 4.4 & 8.6 & 1.5 & 12.8 \\
$\mathrm{Ru}-\mathrm{C} \_\mathrm{M}$ & 30.7 & 27.4 & 0.9 & 4.4 & 6.0 & 3.6 & 8.4 \\
$\mathrm{Ru}-\mathrm{CNF}$ & 6.7 & 33.3 & 4.2 & 0.1 & 12.8 & 0 & 2.2 \\
$\mathrm{Ru}-$ Sib-Imp & 39.4 & 19.5 & 9.4 & 1.0 & 14.9 & 4.1 & 7.7 \\
\hline
\end{tabular}

$X$ conversion of betulin after $4 \mathrm{~h}(\%), S_{1}$ selectivity to betulone (\%), $S_{2}$ selectivity to betulonic aldehyde $(\%), S_{3}$ selectivity to betulonic acid (\%), $S_{4}$ selectivity to betulinic aldehyde (\%), $S_{5}$ selectivity to betulinic acid $(\%), Y_{l}(\%)$ yield of betulone $(\%)$ 

tion over $\mathrm{Ru}-\mathrm{C}_{3} \mathrm{~N}_{4}-\mathrm{MCF}(\mathbf{a})$, $\mathrm{Ru}-\mathrm{C}_{-} \mathrm{M}(\mathbf{b})$ and Ru-Sib-Imp (c)
Fig. 7 Kinetics of betulin oxida-
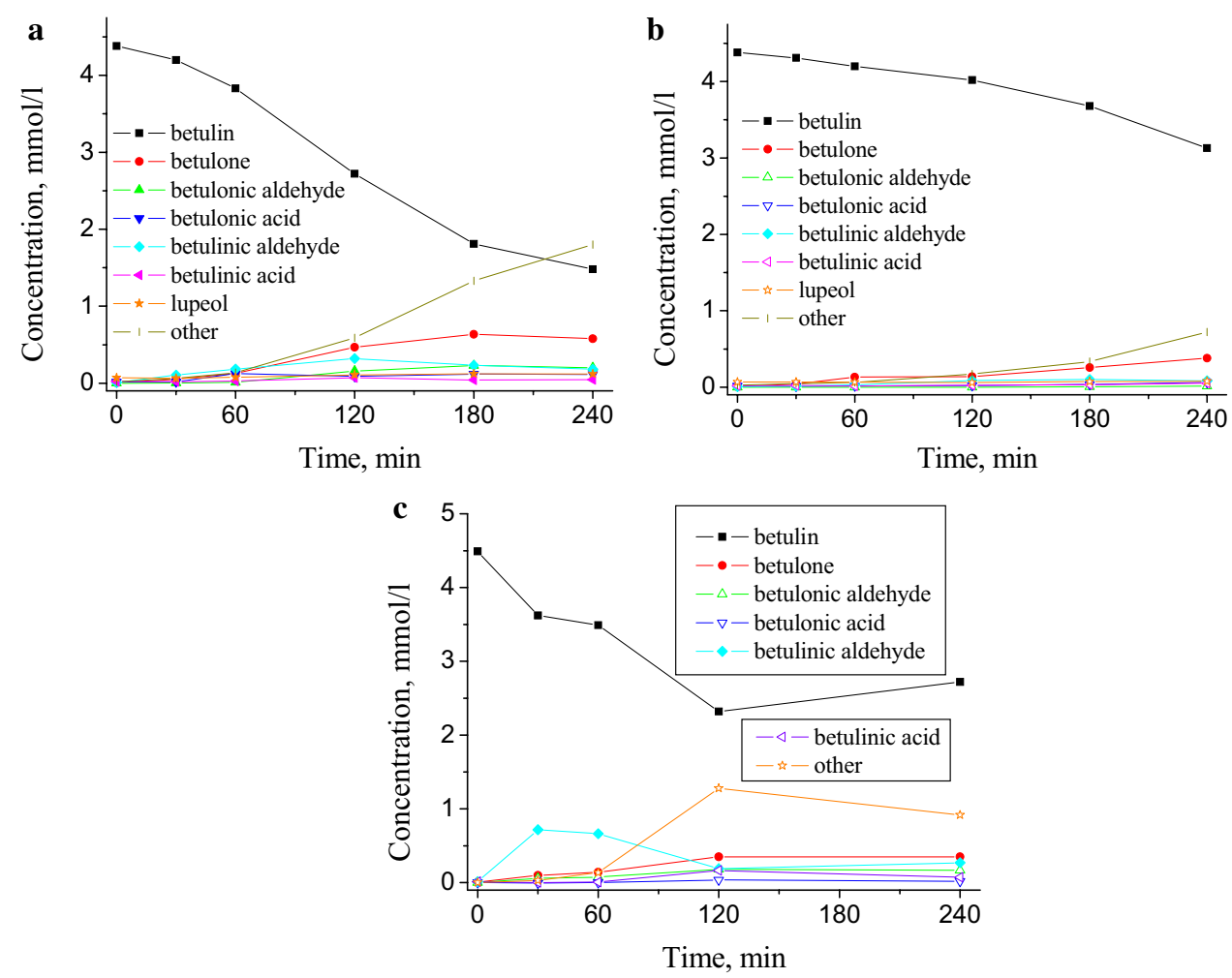

biologically active substances for pharmaceutics) of the State Foundation for Fundamental Research.

\section{Compliance with Ethical Standards}

Conflict of interest The authors declare no conflict of interest.

OpenAccess This article is distributed under the terms of the Creative Commons Attribution 4.0 International License (http://creativeco mmons.org/licenses/by/4.0/), which permits unrestricted use, distribution, and reproduction in any medium, provided you give appropriate credit to the original author(s) and the source, provide a link to the Creative Commons license, and indicate if changes were made.

\section{References}

Fig. 8 Selectivity towards betulone as a function of betulin conversion

Acknowledgements Open access funding provided by Abo Akademi University (ABO). This work is part of the activities at the Johan Gadolin Process Chemistry Centre, a centre of excellence in scientific research financed by Åbo Akademi University. S. Sergienko acknowledges support from the Ministry of Education and Science of the Russian Federation (Increase Competitiveness Program of NUST "MISiS" No. K2-2018-013). The publication contains the results of studies conducted by President's of Ukraine grant for competitive projects (2017; Physicochemical bases of creation of new nanoporous and composite materials based on carbon nitride — catalysts for synthesis of
1. Liu H, Lei XL, Li N, Zong MH (2013) J Mol Catal B Enzym $88: 32$

2. Dzubak P, Hajduch M, Vydra D, Hustova A, Kvasnica M, Biedermann D, Markova L, Urban M, Sarek J (2006) Nat Prod Rep 23:394

3. Alakurtti S, Mäkelä T, Koskimies S, Yli-Kauhaluoma J (2006) Eur J Pharm Sci 29:1

4. Eckerman Ch (1985) Paperi ja Puu 3:100

5. Mäki-Arvela P, Barsukova M, Winberg I, Smeds A, Hemming J, Eränen K, Torozova A, Aho A, Volcho K, Murzin DY (2016) Chem Sel 1:3866

6. Mukharjee R, Kumar V, Srivastava SK, Agarval SK, Burman AC (2006) Med Chem 6:271

7. Tolstikova TG, Sorokina IV, Tolstikov GA, Tolstikov AG, Fletcher OB (2006) J Bioorg Chem 32:37 
8. Haque S, Nawrot DA, Alakurtti S, Ghemtio L, Yli-Kauhaluoma J (2014) PLoS ONE 9:e102696

9. Chung PY, Chung LY, Navaratham P (2013) Res Microbiol 164:319

10. Motteran L, Pilone MS, Molla G, Ghisla S, Pollegioni L (2001) J Biolog Chem 276:18024

11. Das Gupta TK, Pezzuto JM (1997) Pat US 5658947

12. Baltina LA, Flekhter OB, Nigmatullina LR, Boreko EI, Pavlova NI, Nikolaeva SN, Savinova OV, Tolstikov GA (2003) Bioorg Med Chem 13:3549

13. Kogai TI, Kuznetsov BN (2008) Pat RU 2333916

14. Kim DS, Chen Z, Nguyen VT, Pezzuto JM, Qiu S, Lu ZZ (1997) Synth Commun 27:1607

15. Pezzuto JM, Darrick Kim SHL (1998) Pat US 5804575

16. Roshchin VI, Shabanova NYu, Vedernikov DN (2002) Pat RU 2190622

17. Levdansky VA, Polezhaeva NI, Kuznetsov BN (2006) Pat RU 2269541

18. Pichette A, Liu H, Roy C, Tanguay S, Simard F, Lavoie S (2004) Synth Commun 34:3925

19. Komissarova NG, Belenkova NG, Spirikhin LV, Shitikova OV, Yunusov MS (2002) Chem Nat Compd 38:58

20. Csuk R, Schmuck K, Schäfer R (2006) Tetrahedron Lett 47:8769

21. Tulisalo J, Wickholm N, Pirttimaa M, Alakurtti S, Yli-Kauhaluoma J, WO/2013/038312 (Stora Enso Oyj, Helsinki, Finland, 2013)

22. Fuchino H, Satoh T, Hida J, Terada M, Tanaka N (1998) Chem Pharm Bull 46:1051

23. Kim DK, Nam IIY, Kim JW, Shin TY, Lim JP (2002) Arch Pharm Res 25:617

24. Hata K, Hori K, Takahashi S (2002) J Nat Prod 65:645

25. Mutai C, Abatis D, Vagias C, Moreau D, Roussakis C, Roussis V (2004) Phytochemistry 65:1159

26. Dehaen W, Mashentseva AA, Seitembetov TS (2011) Molecules $16: 2443$

27. Zhu J, Xiao P, Li H, Carabineiro SA (2014) ACS Appl Mater Interfaces 6:16449
28. Fan Y, Li X, He X, Zeng C, Fan G, Liu Q, Tang D (2014) Int J Hydrogen Energy 39:19982

29. Kim M, Hwang S, Yu JS (2007) J Mater Chem 17:1656

30. Lin B, Wang R, Lin J, Du S, Yu X, Wei K (2007) Catal Commun $8: 1838$

31. Simakova IL, Demidova YS, Gläsel J, Murzina EV, Schubert T, Prosvirin IP, Etzold BJM, Murzin DY (2016) Catal Sci Technol 6:8490

32. Delidovich IV, Taran OP, Matvienko LG, Simonov AN, Simakova IL, Bobrovskaya AN, Parmon VN (2010) Catal Lett 140:14

33. Gregg SG, Sing KSW (1982) Adsorption, surface area and porosity. Academic Press, New York

34. Barrett EP, Joyner LG, Halenda PP (1951) J Am Chem Soc 73:373

35. Horvath G, Kawazoe K (1983) J Chem Eng Jpn 16:470

36. Eckerman C, Ekman R (1985) Paperi ja Puu 67:100

37. Harold PK, Leroy EA (1974) X-ray diffraction procedures: for polycrystalline and amorphous materials. Wiley, New York

38. Datta KKR, Reddy BV, Ariga K, Vinu A (2010) Angew Chem Int Ed 49:5961

39. Qadir K, Joo SH, Mun BS, Butcher DR, Renzas JR, Aksoy F, Liu Zh, Somorjai GA, Park JY (2012) Nano Lett 12:5761

40. Chakroune N, Viau G, Ammar S, Poul L, Veautier D, Chehimi MM, Mangeney C, Villain F, Fiévet F (2005) Langmuir 21:6788

41. Aho A, Roggan S, Simakova O, Salmi T, Murzin DYu (2015) Catal Today 241:195

42. Aho A, Roggan S, Eränen K, Salmi T, Murzin DYu (2015) Catal Sci Technol 5:953

43. Long B, Lin J, Wang X (2014) J Mater Chem A 2:2942

44. Joo SH, Park JY, Renzas JR, Butcher DR, Huang WY, Somorjai GA (2010) Nano Lett 10:2709

Publisher's Note Springer Nature remains neutral with regard to jurisdictional claims in published maps and institutional affiliations. 